\title{
Surgical Exposure Gained in an Extended Retrosigmoid Approach to the Cerebellopontine Angle Compared to the Traditional Retrosigmoid Approach
}

\section{Genişletilmiş Retrosigmoid Yaklașım ile Serebellopontin Köşseye Ulaşımda Cerrabi Alan Kazanılması ve Geleneksel Yöntemle Karşılaştırılması}

\author{
Davut CEYLAN ${ }^{1}$, Necati TATARLI ${ }^{2}$, Askin SEKER ${ }^{3}$, Safiye CAVDAR ${ }^{4}$, Turker KILIC ${ }^{5}$ \\ 1 Sakarya University, School of Medicine, Department of Neurosurgery, Sakarya, Turkey \\ ${ }^{2}$ Dr. Lutfi Kirdar Kartal Education and Research Hospital, Department of Neurosurgery, Istanbul, Turkey \\ ${ }^{3}$ Marmara University, School of Medicine, Institute of Neurological Sciences, Department of Neurosurgery, Istanbul, Turkey \\ ${ }^{4}$ Koc University School of Medicine, Department of Anatomy, Istanbul, Turkey \\ ${ }^{5}$ Bahcesebir University, School of Medicine, Department of Neurosurgery, Istanbul, Turkey
}

Corresponding Author: Davut CEYLAN / E-mail: davutceylan@yahoo.com.tr

\begin{abstract}
AIM: Retrosigmoid approach to the posterior fossa has been a popular and dependable approach for accessing the cerebellopontine angle (CPA) and petroclival region. Although this approach is commonly used, it requires cerebellar retraction and has limitations when the lesion is located ventral to the brainstem. The aim was to quantify the angle of view provided by extended retrosigmoid approach in comparison to the traditional approach. A secondary objective was to identify a strategic initial burr hole site for craniotomy.

MATERIAL and METHODS: Ten adult human cadaver heads (20 sides) were used. First, traditional retrosigmoid approach was performed and the angle of exposure was measured on cranial computerized tomography (CT). Following, extended retrosigmoid approach was performed with mastoid bone drilling and reflection of venous sinuses. Angle of exposure was measured on CT. Two measurements of both approaches were compared.

RESULTS: Mean angle of view for the traditional retrosigmoid approach $\left(31.4^{\circ} \pm 4.1^{\circ}\right)$ was significantly smaller than that of the extended approach $\left(46.0^{\circ} \pm 4.7^{\circ}\right)(p<0.001)$. Site of strategic burr hole was $5 \mathrm{~mm}$ below and $15 \mathrm{~mm}$ lateral to the asterion was defined.

CONCLUSION: Extended retrosigmoid approach offers neurosurgeons approximately $50 \%$ larger angle of view and shorter working distance than the traditional approach provides. This modification permits better access to the CPA and ventral brain stem without cerebellar retraction.
\end{abstract}

KEYWORDS: Cerebellopontine angle, Extended retrosigmoid approach, Retrosigmoid approach

öz

AMAÇ: Serebellopontin köşe ve petroklival alana ulaşım için retrosigmoid yaklaşım yaygın kullanılan ve güvenilir bir yöntemdir. Ancak bu yaklaşımda, özelliklede lezyonun beyin sapının ventralinde olduğu durumlarda serebellar retraksiyon gerektiğinden, yöntemin kısıtlamaları bulunmaktadır. Çalışmada amaç, genişletilmiş retrosigmoid (ERS) yaklaşımla kazanılan görüş açısının miktarının belirlenmesi ve geleneksel yöntemle (TRS) karşılaştırılmasıdır. İkincil amaç ise, bu yaklaşım için stratejik burr hole yerinin tespit edilmesidir.

YÖNTEM ve GEREÇLER: On yetişkin insan kadavra kafası (20 bölge) kullanıldı. Önce TRS yaklaşımı uygulanarak elde edilen görüş açısı kranial BT kullanılarak ölçüldü. Daha sonra mastoid kemiğin drillenmesi ve venöz sinüslerin refleksiyonu ile ERS yaklaşımı uygulandı. Aynı ölçümler bu yöntemde de elde edildi. İki yaklaşımın ölçümleri karşılaştırıldı.

BULGULAR: Geleneksel yaklaşımla elde edilen görüş açısı ortalaması $\left(31,4^{\circ} \pm 4,1^{\circ}\right)$, genişletilmiş yaklaşımla elde edilen değerden $\left(46,0^{\circ} \pm 4,7^{\circ}\right)$ istatiksel olarak anlamlı düzeyde düşük bulundu $(\mathrm{p}<0,001)$. Stratejik burr hole alanı olarak asterionun $5 \mathrm{~mm}$ altı ve $15 \mathrm{~mm}$ laterali belirlendi.

SONUÇ: ERS yaklaşımı, TRS yaklaşımına göre yaklaşık olarak \%50 daha fazla görüş açısı kazandırmaktadır. Bu modifikasyon serebellar retraksiyon yapmadan CPA ve beyin sapının ventraline daha iyi ulaşım olanağı sağlamaktadır.

ANAHTAR SÖZCÜKLER: Serebellopontin köşe, Genişletilmiş retrosigmoid yaklaşım, Retrosigmoid yaklaşım 


\section{INTRODUCTION}

In the early 1990s, surgeons operating on the cranial base developed radical approaches to the posterior cranial fossa. They removed large pieces of bone and created wider access using translabyrinthine, retrolabyrinthine, transcochlear, or middle fossa approaches in order to minimize brain retraction $(2,5,6,10,12,21)$. These radical approaches to the skull base require time to perform and are associated with significant morbidity $(2,4,5,10,12,16,20,21)$. Development of microsurgical techniques, improved instrumentation, and advanced preoperative diagnostic equipment have enabled neurosurgeons to treat complicated cranial lesions with less invasive surgery that involves more specific, targeted approaches and with less brain exposure and tissue retraction.

The conventional retrosigmoid approach to the posterior fossa has been popular and dependable for accessing lesions in the cerebellopontine angle (CPA) and the petroclival region $(8,9,11,13,14)$. This approach is commonly used but requires cerebellar retraction and has limitations for lesions located ventral to the brainstem. There is need for an alternative approach that provides adequate exposure, less morbidity, and can be performed more quickly and simply. The extended retrosigmoid approach to the skull base is a newer method that requires more extensive removal of the mastoid portion of the temporal bone, specifically the bone overlying the sigmoid sinus. This extended approach has also become popular for lesions located in the CPA, and particularly those that involve the ventral brainstem.

Our aim in this study was to quantify the increase in angle of view that the extended retrosigmoid approach provides in comparison to the traditional retrosigmoid approach. We also used morphometric measurements to evaluate the relationship between the asterion and the transverse and sigmoid sinuses, and to identify safe and strategic sites for placement of the initial burr hole for craniotomy in patients with lesions of the CPA.

\section{MATERIAL and METHODS}

The heads of 10 formalin-fixed adult human cadavers (3 females, 7 males, age range 57-78 years) were used. Arteries were injected with red silicon via the internal carotid artery, and veins were injected with blue silicon via the internal jugular vein. The left and right sides of the 10 heads were evaluated (20 specimens total). Each head was positioned laterally and fixed with a Mayfield clamp, and the hair was shaved to expose the incision area. Dissections were performed using standard microsurgical instruments and a surgical microscope.

\section{Skin and Soft-Tissue Dissection}

The asterion, a landmark on the cranium located at the intersection of the parietomastoid, lambdoid, and occipitomastoid sutures, was palpated. The skin was incised from 2-3 cm superior to the asterion to $2-3 \mathrm{~cm}$ below the mastoid tip.The superior end of the incision curved parallel to the pinna anteriorly, and the inferior end curved posteriorly away from the mastoid tip, thus forming a letter $S$ on the right side and a reverse $S$ on the left (Figure 1). The soft tissue underlying the incision was dissected. The superficially located occipitofrontalis and sternocleidomastoid muscles were dissected. The semispinalis capitis muscle, deeply situated and partially covered by the splenius capitis and sternocleidomastoid muscles, was detached from its bony attachments and retracted (Figures 2A, B). The facial and greater occipital nerves and the occipital artery were identified and preserved (Figures 2A-C). Self-retaining retractors were used to achieve the necessary retraction. The pericranium was reflected caudally. The parietomastoid, occipitomastoid, and lambdoid sutures were identified on the bone surface, and the asterion was visualized. For each of the 20 specimens, further dissection was then performed in two steps: a traditional retrosigmoid approach followed by an extended retrosigmoid approach.

\section{Traditional Retrosigmoid Approach}

A burr hole was made $5 \mathrm{~mm}$ inferior and $15 \mathrm{~mm}$ lateral to the asterion, exposing the junction of the transverse and sigmoid sinuses (Figures 3A, B). To standardize the craniotomy, an imaginary horizontal line was drawn between the lateral border of the sigmoid sinus and the external occipital protuberance, and the dissected area was divided into thirds: medial, middle, and lateral (Figure 4). A posterolateral suboccipital craniotomy was then performed along the lateral third of the imaginary line using a high-speed drill with a cutting tip. This exposed the lateral margins of the sigmoid and transverse sinuses. This approach typically leaves the major venous sinuses encased in bone (7). Next, a Y-shaped incision was made in the dura and the dura was retracted against the sigmoid and transverse sinuses. A cutting drill tip was used to make 7 or 8 small holes in the bone edges, and these were used to suture the dura over the drilled mastoid

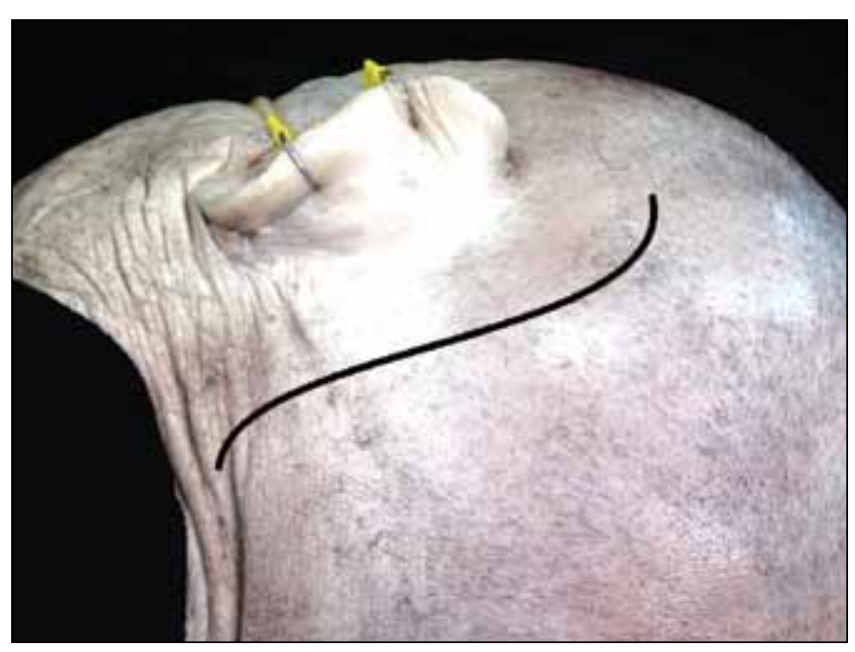

Figure 1: The incision started $2-3 \mathrm{~cm}$ superior to the asterion and extended $2-3 \mathrm{~cm}$ below mastoid tip. The superior and inferior ends were curved, forming a letter $S$ on the right-side specimens and a reverse $S$ on left-side specimens. 

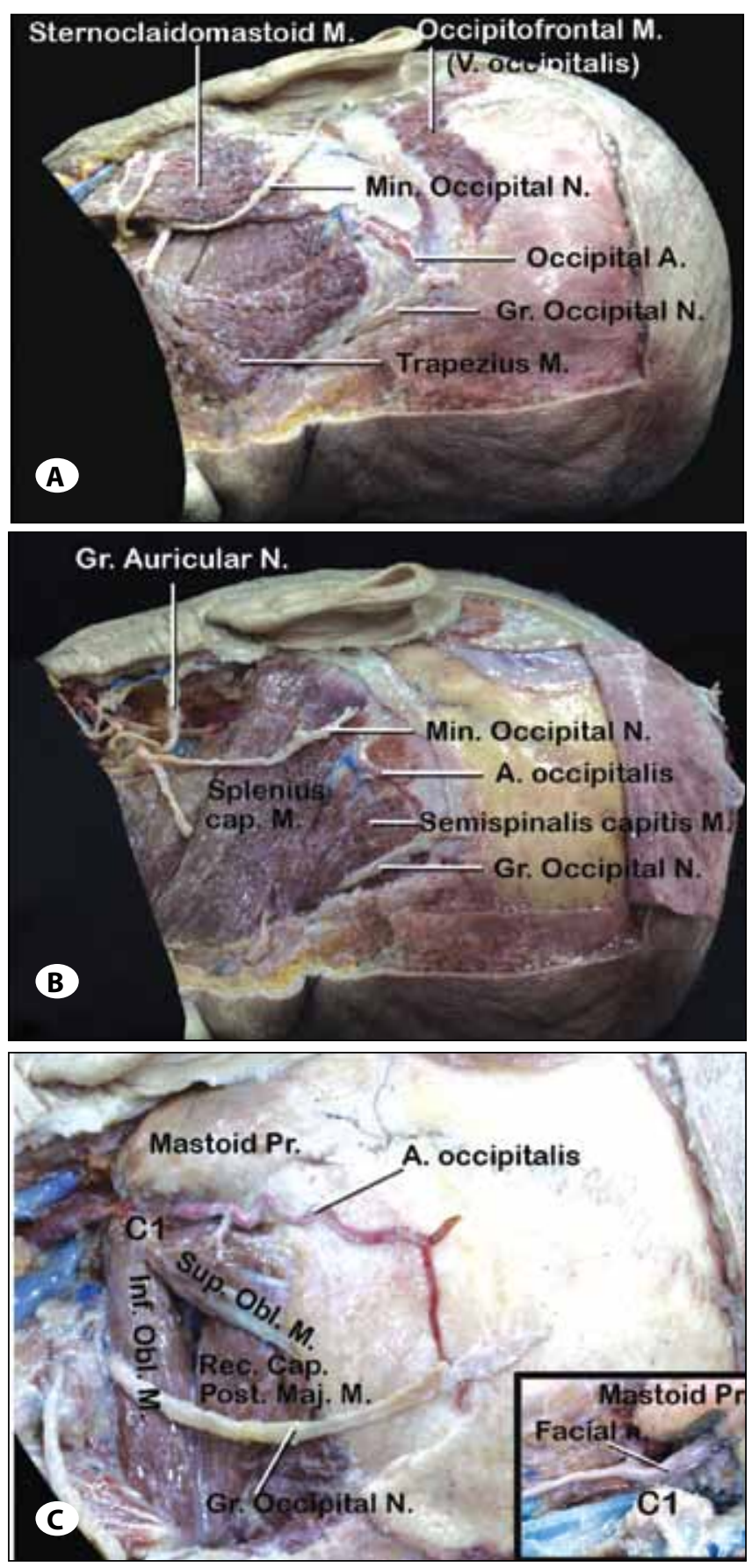

Figure 2: Soft-tissue dissection: A) The skin over the mastoid region was reflected and the trapezius, sternocleidomastoid, occipitofrontalis, and splenius capitis muscles were exposed. Note that the terminal portion of the occipital artery and the retroauricular and greater occipital nerves were also exposed; B) The trapezius, sternocleidomastoid, occipitofrontalis, and galea, with periosteum were then retracted. The greater auricular nerve, minor occipital nerve, greater occipital nerve, splenius capitis, semispinalis capitis, and occipital artery were exposed; C) Further dissection exposed the suboccipital triangle and the entire trajectories of the greater occipital nerve and the occipital artery. The inset shows the facial nerve exiting from the stylomastoid foramen in the digastric groove. so that the dura remained in this position for imaging. Axial cranial computerized tomography (CT) was performed to quantify surgical exposure (see details below).

\section{Extended Retrosigmoid Approach}

Next, the mastoid portion of the temporal bone was drilled and the part overlying the sigmoid sinus was removed, exposing the sinus (Figures 5A, B). A similar classical Y-shaped dural opening was made in this approach; however, because the sigmoid sinus was skeletonized, it was possible to retract the dura further than in the traditional approach, and thus reflect the sigmoid sinus itself. This provided a clear view of the deeper neurovascular structures and the suboccipital surface of the cerebellum (Figures 6A, B). The dura was secured over the mastoid bone with sutures and axial CT was repeated to quantify surgical exposure (see details below).

\section{Computerized Tomography Measurements}

On each of the 40 CT scans, we quantified surgical exposure using measurements and calculations from a specific angle.
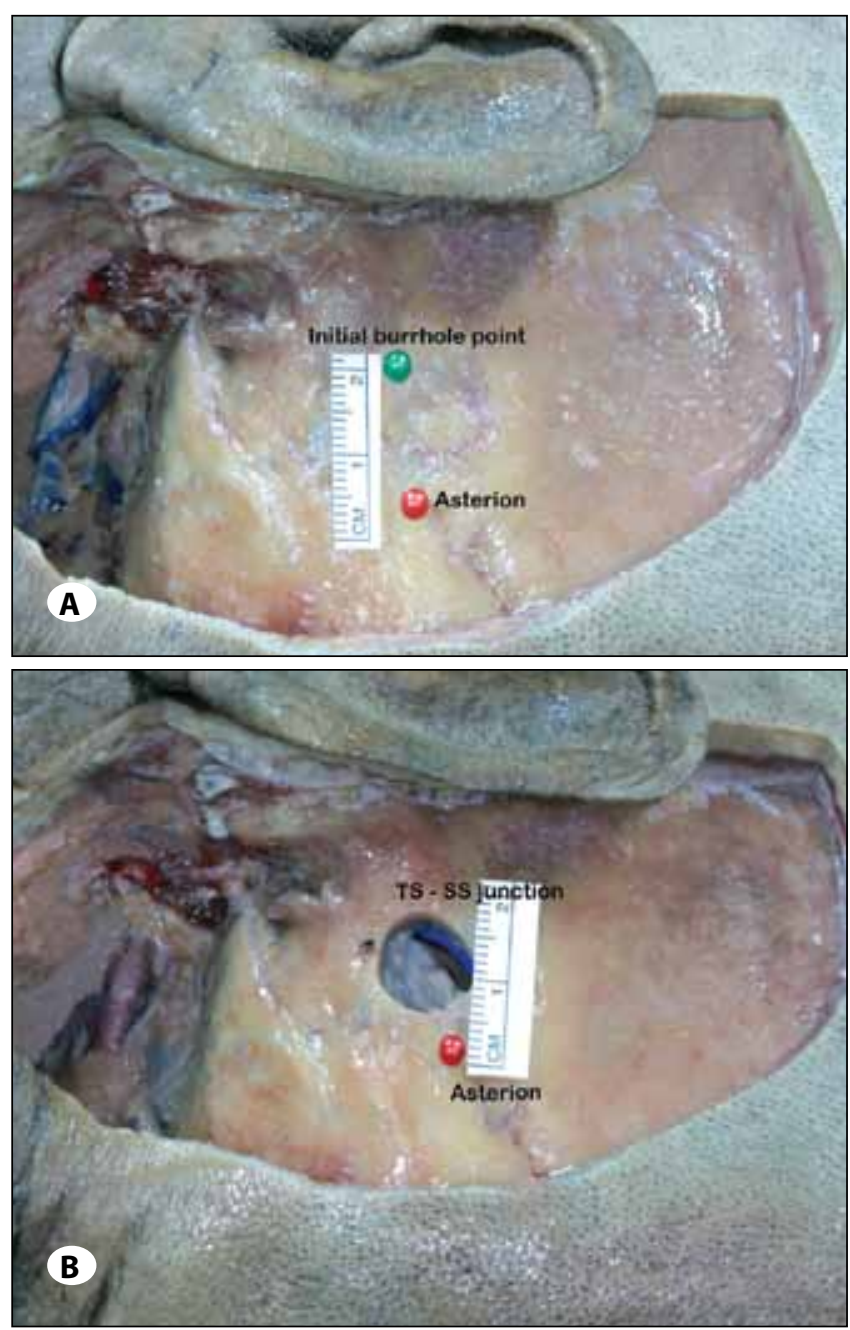

Figure 3: The asterion (red needle head) was identified and the burr hole (green needle head) was made $5 \mathrm{~mm}$ below and $15 \mathrm{~mm}$ lateral to it. 
The vertex of this angle was at the suprameatal tubercle which is a centered surgical landmark around this area, its longer arm extended from the vertex along the medial edge of the craniotomy over the cerebellar convexity, and its shorter arm extended from the vertex along the lateral edge of the craniotomy over the sigmoid sinus (Figures 7A, B). An imaginary line was drawn between the two arm tips at the level of the craniotomy borders to form the base of a triangle. In the traditional retrosigmoid approach, this line was called "y1." In the extended approach, this line was called "yt" (Figure $8)$, and it comprised y1 plus "y2," which was the extra distance

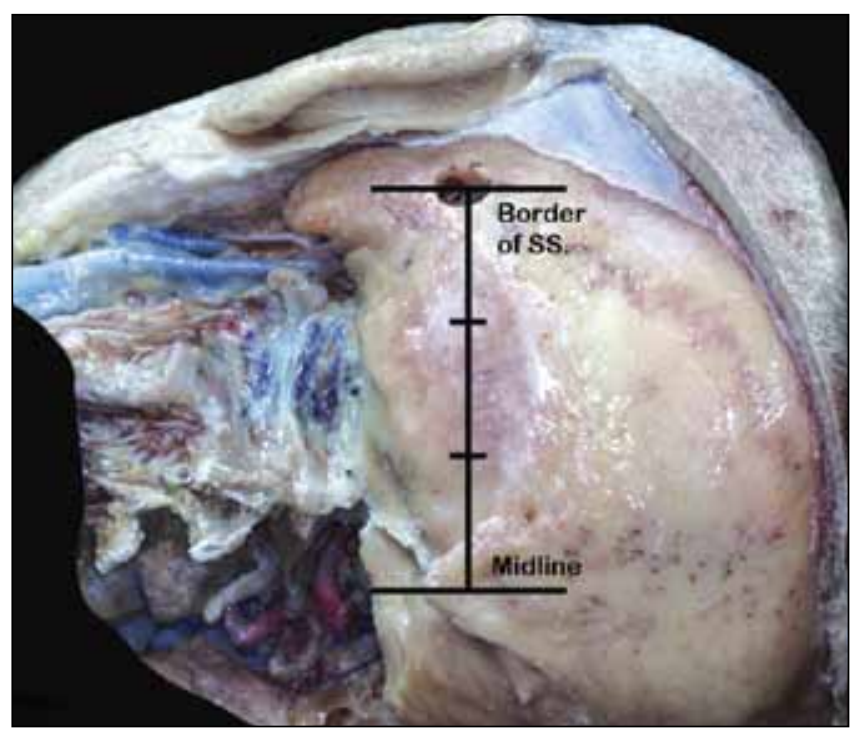

Figure 4: On each specimen, an imaginary horizontal line was drawn between the lateral border of the sigmoid sinus (SS) and the external occipital protuberance, and the dissected area over the bone was divided into thirds: medial, middle, and lateral. A posterolateral suboccipital craniotomy was then made along the lateral third of this line.

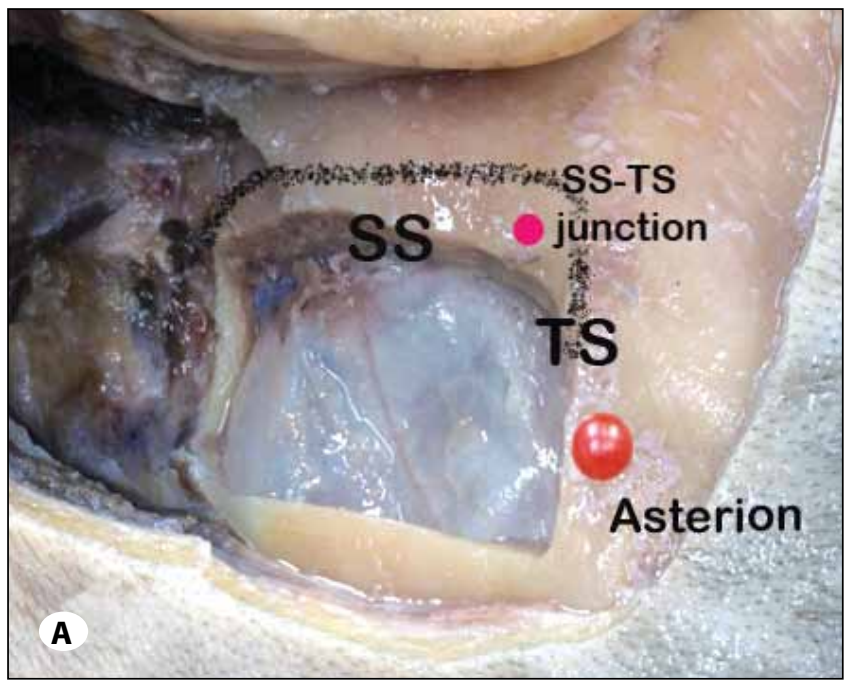

that the triangle base spanned over the sigmoid sinus. This extra distance meant that working distance depth was shallower using the modified approach.

In addition to evaluation of working distance, we measured angle of view in degrees for the angle defined above. This was done according to the inverse tangent concept of the Pythagorean Theorem, using the software program syngofast View (Siemens Medical SW, Erlangen, Germany). The angle of view measured with the traditional retrosigmoid approach was called "a1," and that measured with the extended approach was called "a2."

\section{Morphometric Measurements}

We used a digital compass to make 2 measurements on each side of each cadaver head (i.e., 40 morphometric measures total) (Figures 9A, B). First, we measured the distance in millimeters from the lower border of the transverse sinus to the asterion. In cases where the inferior border of the transverse sinus was above the asterion, the distance was recorded as negative. In cases where the inferior border was below the asterion, the distance was recorded as positive. Second, we measured the distance in millimeters from the medial border of the transverse-sigmoid sinus junction to the asterion.

\section{Statistical Analyses}

Student's $t$ test was used to compare mean angles of view for the traditional versus the extended retrosigmoid approach for the 20 specimens overall. To compare the mean angles of view for the left sides versus right sides with each approach student's $t$ test was used. The same analysis was used to compare the mean distance from the medial border of the transverse-sigmoid sinus junction to the asterion on the left sides versus the right sides of the 10 heads. A $p$ value less than 0.05 was considered significant.

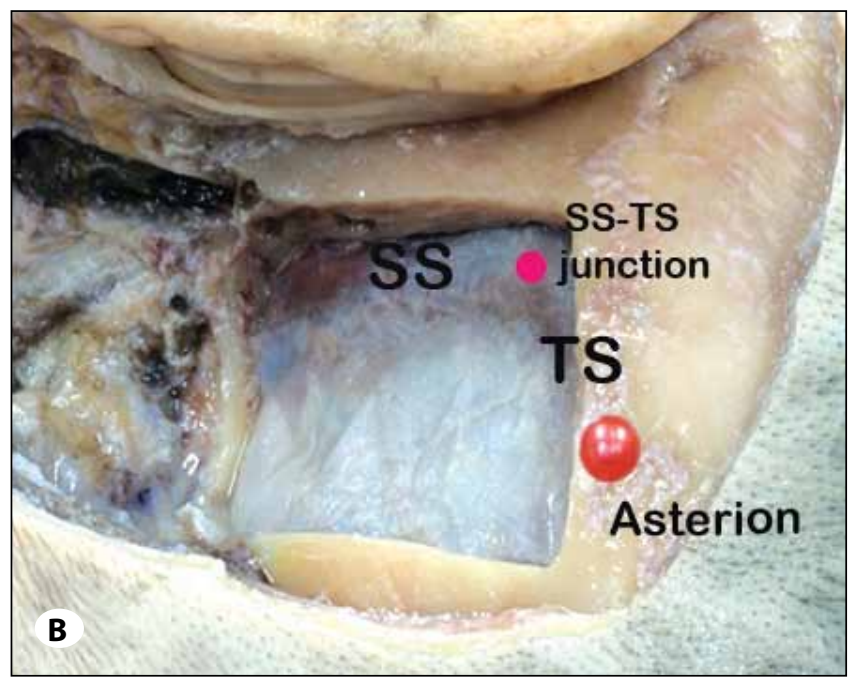

Figure 5: Bone dissection: A) In the traditional retrosigmoid approach, the bone over the sigmoid sinus is not skeletonized. The dotted line outlines the transverse sinus (TS), sigmoid-transverse (SS-TS) junction, and sigmoid sinus (SS) beneath the mastoid bone; B) In the extended retrosigmoid approach, the bone over the SS-TS junction and SSis skeletonized. 

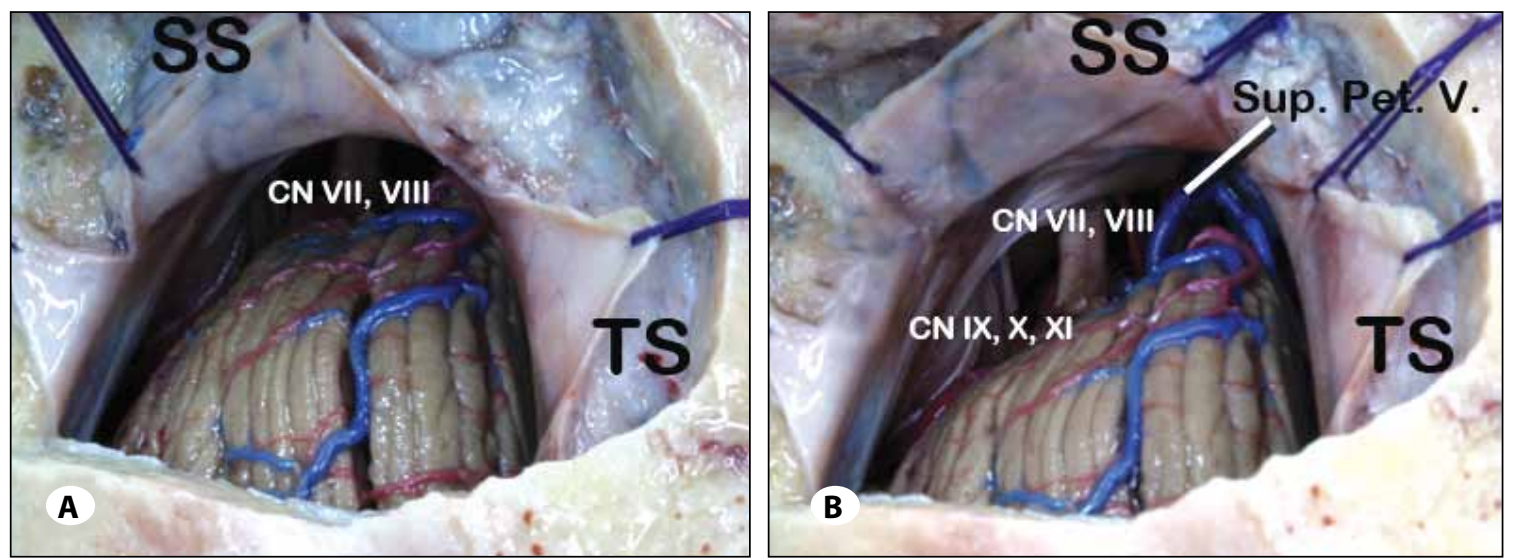

Figure 6: Dural part A) The traditional retrosigmoid approach with the dura reflected over the sigmoid sinus (SS) and transverse sinus (TS), and the resulting exposure; B) The extended retrosigmoid approach with the dura reflected over the mastoid, and wider exposure compared to the traditional approach.

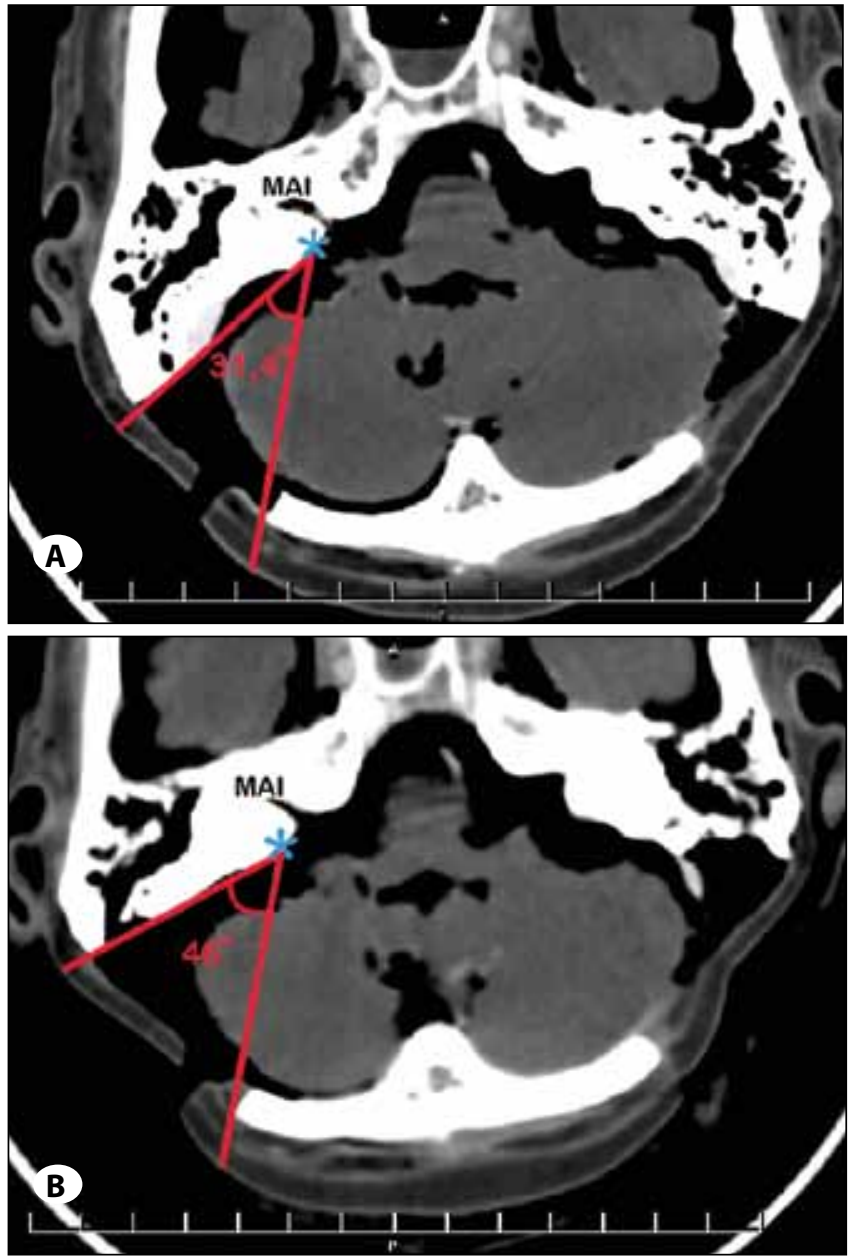

Figure 7: Angle measurements were taken from axial cranial computed tomography scans performed after the traditional (A) and extended (B) retrosigmoid approaches were performed. A specific angle was defined for this study, with vertex at the suprameatal tubercle $\left({ }^{*}\right)$, one arm along the medial edge of the craniotomy over the cerebellar convexity, and the other arm extending along the lateral edge of the craniotomy over the sigmoid sinus (MAl: meatus acousticus internus).

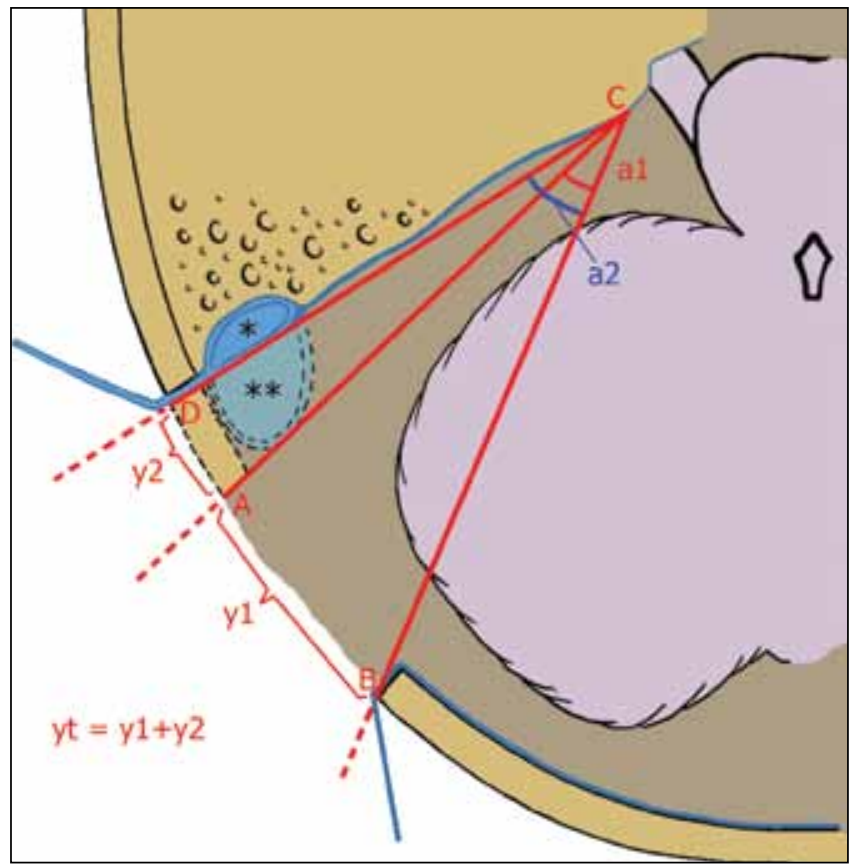

Figure 8: Angle measurements were based on the inverse tangent concept of the Pythagorean Theorem, with $y 1$ the length of the base of the triangle created by the angle of view with the traditional retrosigmoid approach; y2 the portion of the base of the triangle representing the skeletonized sigmoid sinus; yt $=y 1+y 2$, or the total length of the base of the triangle created by the angle of view with the extended retrosigmoid approach. Angles a1 and a2 were the angles of view obtained with the traditional and extended approaches, respectively.

* lumen of the sigmoid sinus, which is reflected during the extended retrosigmoid approach; ** lumen of the sigmoid sinus after the dura and sigmoid sinus have been reflected during the extended retrosigmoid approach. 


\section{RESULTS}

For all left and right specimens combined (i.e., the 20 sides total), the means for $y 1$ and yt were $24.8 \mathrm{~mm} 35.5 \mathrm{~mm}$, respectively. The mean angle of view for the traditional retrosigmoid approach (mean a $1,31.4^{\circ} \pm 4.1^{\circ}$ ) was significantly smaller than that for the extended approach (mean a2, $46.0^{\circ}$ $\left.\pm 4.7^{\circ}\right)(p<0.001)$.

Table I lists the angle of view result with each surgical approach for the left and right side of each cadaver head. Mean a1 on the right side was $31.2^{\circ} \pm 4.1^{\circ}$ (range, $25.7^{\circ}$ to $37.8^{\circ}$ ) and on the left was $31.6^{\circ} \pm 3.9^{\circ}$ (range, $24.2^{\circ}$ to $37.9^{\circ}$ ). The corresponding findings for a 2 were $45.6^{\circ} \pm 3.8^{\circ}$ on the right (range, $40.6^{\circ}$ to $53.2^{\circ}$ ) and $46.4^{\circ} \pm 5.3^{\circ}$ (range, $40.9^{\circ}$ to $58.7^{\circ}$ ) on the left.

The lower border of the transverse sinus was located $5 \mathrm{~mm}$ (range, 4-5 $\mathrm{mm}$ ) below the asterion in 18 of the cadaver-head sides. This border was $5 \mathrm{~mm}$ above the asterion on the right side in one head, and $1 \mathrm{~mm}$ above the asterion on the left side in another head.

The mean distance between the medial border of the transverse-sigmoid sinus junction and the asterion was 17.1

Table I: Results for Angle Measurements with the Traditional and Extended Retrosigmoid Approaches

\begin{tabular}{|c|c|c|c|c|}
\hline \multirow[b]{2}{*}{ Cadaver } & \multicolumn{2}{|c|}{ Angle with traditional approach } & \multicolumn{2}{|c|}{ Angle with extended approach } \\
\hline & Right & Left & Right & Left \\
\hline 1 & 33.9 & 34.1 & 47.1 & 48.9 \\
\hline 2 & 37.7 & 37.9 & 53.2 & 58.7 \\
\hline 3 & 31.4 & 36 & 43.2 & 45.9 \\
\hline 4 & 32.2 & 32.3 & 42.6 & 45.5 \\
\hline 5 & 37.8 & 28.9 & 51.1 & 43.7 \\
\hline 6 & 29.7 & 24.2 & 45.5 & 42.9 \\
\hline 7 & 30.4 & 33.6 & 42.4 & 40.9 \\
\hline 8 & 27.3 & 29.5 & 47.2 & 42.6 \\
\hline 9 & 25.8 & 27.2 & 43.4 & 41.8 \\
\hline 10 & 25.7 & 32.2 & 40.6 & 52.8 \\
\hline Mean & 31.2 & 31.6 & 45.6 & 46.4 \\
\hline SD & 4.1 & 3.9 & 3.8 & 5.3 \\
\hline Max & 37.8 & 37.9 & 53.2 & 58.7 \\
\hline Min & 25.7 & 24.2 & 40.6 & 40.9 \\
\hline
\end{tabular}
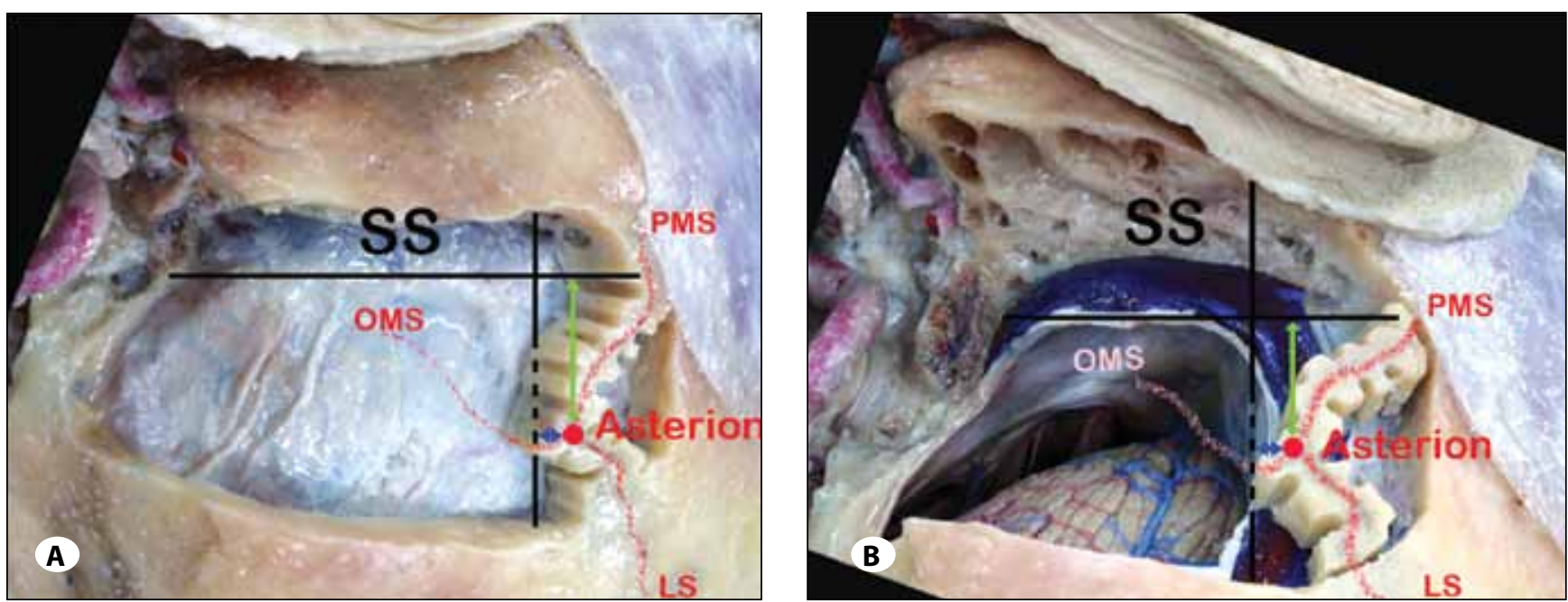

Figure 9: The horizontal line depicts the lower border of the transverse sinus, and the vertical line depicts the medial border of the sigmoid sinus (SS). Both lines intersect at the transverse-sigmoid sinus junction. Dotted red lines identify the parietomastoid suture (PMS), occipitomastoid suture (OMS), and lambdoid suture (LS). For mophometric analyses, the distance from the lower border of the transverse sinus to the asterion (distance depicted by the blue line), and the distance from the medial border of the sigmoid sinus to the asterion (green line) were measured. A) The extended retrosigmoid approach with the dura over the sinuses intact; B) View with the dura over the sinuses removed and with blue silicon filling the sinuses to delineate these structures. 
$\mathrm{mm}$ (range, $12-25 \mathrm{~mm}$ ) on the right and $15.2 \mathrm{~mm}$ (range, 11-20 $\mathrm{mm}$ ) on the left. These means were not significantly different.

\section{DISCUSSION}

Our main findings were $i$ ) the extended retrosigmoid approach provides approximately 50\% wider angle of view than the traditional approach; ii) the transverse sinus was typically located approximately $5 \mathrm{~mm}$ below the asterion; iii) the average distance between the sigmoid sinus and the asterion was $17.1 \mathrm{~mm}$ on the right side and $15.2 \mathrm{~mm}$ on the left.

\section{Comparison of the Traditional and Extended Retrosigmoid Approaches}

The first traditional retrosigmoid approach was introduced by Kress in the early 1900s, and this method has been popular for accessing lesions of the posterior fossa. However, while this approach provides access to the CPA, extreme cerebellar retraction is necessary to expose ventral brain stem and to create wider surgical corridor. To address this, many surgeons $(20,23)$ emphasized the importance of extending the retrosigmoid approach laterally to reach large tumors. Quinones-Hinojosa et al. and Raza and Quinones-Hinojosa published a clinical series in which they used an extended retrosigmoid approach for lesions of the CPA, but neither of these papers provided a detailed description of this technique $(15,16)$.

Our study and others have described modifications of the standard retrosigmoid approach that involve mastoidectomy and skeletonizing the sigmoid sinus $(15,16,19)$. In all these methods, the retrosigmoid approach is extended laterally by drilling the mastoid bone anterolaterally and exposing the sigmoid sinus and the sigmoid-transverse sinus junction. With the sigmoid sinus skeletonized and retracted laterally by the dural flap, the surgeon gains wider access to the CPA and to nearby cranial nerves and vascular structures. Thus, extended approach provides a clear view of the cranial nerves without retracting the cerebellum (Figures 10A, B). For the traditional exposure, cerebellar retraction was necessary to obtain same view (Figure 10C).

In our study, to make standard methodological measurement we have chosen suprameatal tubercle which is a constant at one point for each cadaveric specimen. Additionally, meatal tubercle is a surgical landmark, which is centering anatomical structure around this area. Additionally, in Abolfotoh $M$ et al.'s recent coincidental and clinical study, they also used suprameatal tubercule as a landmark point in their measurements, which supports our method (1). We found that the angle of view with the traditional retrosigmoid approach was $31.4^{\circ}$, whereas skeletonizing the sigmoid sinus increased this to $46.0^{\circ}$. Thus, $10 \mathrm{~mm}$ of skeletonizing over the sigmoid sinus can enhance operational capabilities by providing a $50 \%$ larger angle of exposure. In addition to increasing angle of view, the extended retrosigmoid approach reduces the surgical working distance in the area of the CPA by making a deeply situated lesion more superficial, thus reducing the need for cerebellar retraction.
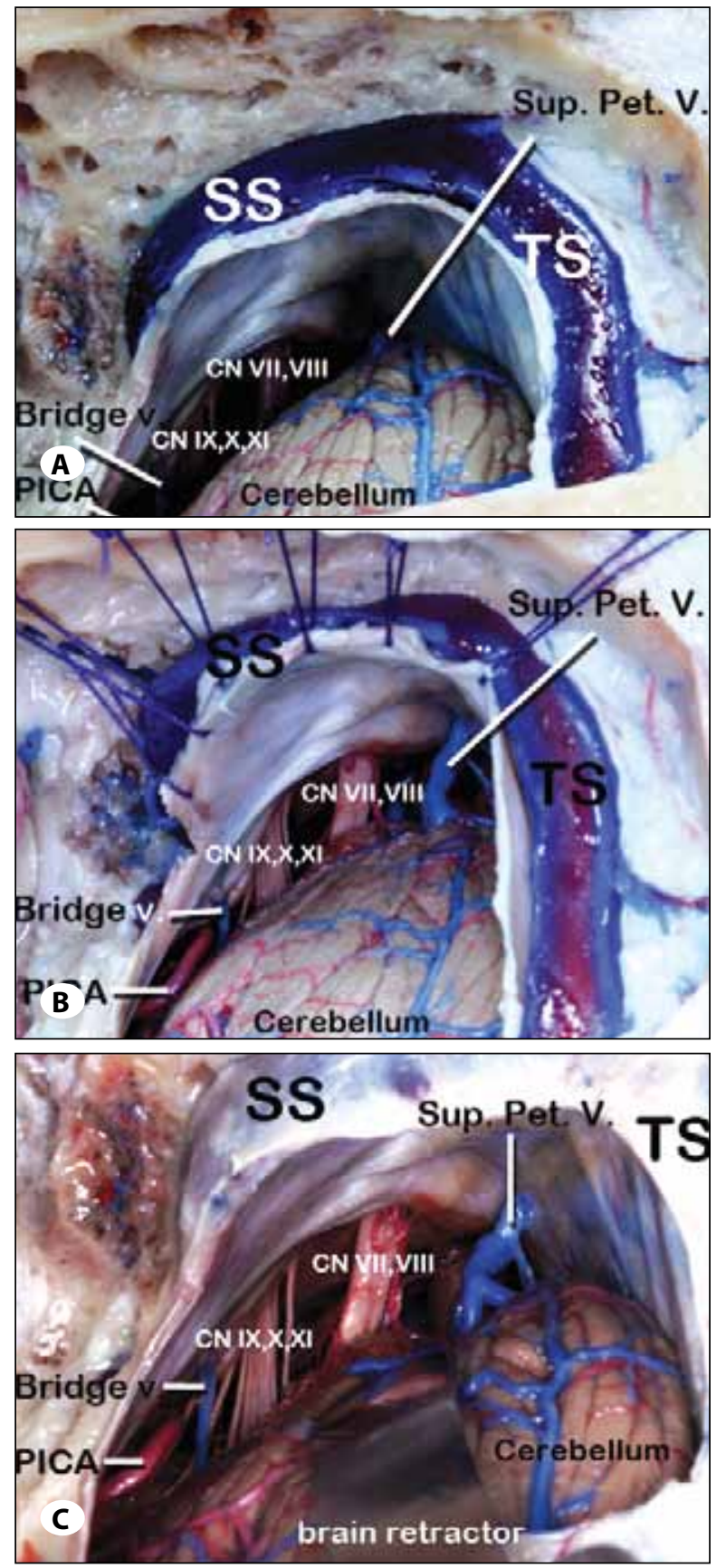

Figure 10: Comparison of overall views of the two approaches: A) Anatomical structures typically exposed during the traditional retrosigmoid approach. Note the limited exposure of the superior petrosal vein, the anterior inferior cerebellar artery, the posterior inferior cerebellar artery (PICA), and the facial (CN VII) and vestibulocochlear (CN VIII) nerves; B) The extended retrosigmoid approach provides better exposure of the superior petrosal vein, anterior inferior cerebellar artery, PICA, and the facial (CN VII), vestibulocochlear (CN VIII), trigeminal (CN V), abducens (CN VI), glossopharyngeal (CN IX), vagus (CN X), accessory (CN XI), and hypoglossal (CN XII) nerves; C) in the traditional retrosigmoid approach, excessive retraction of the cerebellum is necessary to obtain a similar angle of view to that achieved with the extended retrosigmoid approach. (SS: sigmoid sinus; TS: transverse sinus). 
The traditional retrosigmoid approach provides limited exposure of the sigmoid sinus and results in a ledge of bone overlying the path of access to the CPA. As noted, this compromises surgical exposure and necessitates cerebellar retraction. The extended technique is rapid, safer, and easier than radical approaches to the skull base, and it can be used for surgical management of a variety of CPA lesions. ERS has several advantages, in terms of accessing tumor/cysts or vascular malformations that are difficult to reach with traditional approach, including increasing the working area, avoiding retraction on the cerebellum and improving surgical maneuver ability (2). As well, depending on the site and size of the lesion, the traditional retrosigmoid approach can be extended in various directions. While we investigated lateral extension over the sigmoid sinus, geometric calculations reveal that removing bone medial to the traditional craniotomy (as opposed to lateral to it) would result in a $39^{\circ}$ angle of view. Based on our finding that the angle of view with the traditional approach was $31.4^{\circ}$, this medial extension would provide only $24 \%$ increased exposure.

With the laterally extended retrosigmoid approach, there is risk of tearing the transverse and/or sigmoid sinus during skeletonization; however, this is unlikely if the bone over the sinuses is drilled with caution and instead cutting by craniotome crossing over them. Further, reflecting the sigmoid sinus may seem precarious with respect to maintaining its patency; however, studies suggest that risk of blockage is minimal $(15,16)$. The inferior surface of the sigmoid sinus sits in a deep notch on the temporal bone, and only the anterior surface of this sinus is skeletonized in the extended approach. This anatomical configuration helps maintain sigmoid sinus patency under normal circumstances, and it may also prevent occlusion when the sinus is mobilized during surgery. If occlusion does occur due to reflection of the sigmoid sinus on one side, the contralateral sinus remains open. Also, it has been shown that this maneuver can partially obstruct the lumen of the sinus without resulting in thrombosis or venous infarction (15). Raza and Quinones-Hinojosa (16) reported one clinically silent case of venous obstruction among 15 patients with neoplastic posterior fossa lesions who underwent the extended retrosigmoid approach. Quinones-Hinojosa et al. (15) reported on 38 patients with cerebrovascular lesions who underwent this approach, and none of these individuals developed venous obstruction of the sigmoid sinus.

For patients who are scheduled to undergo the extended retrosigmoid approach, it is important to evaluate the transverse and sigmoid sinuses preoperatively to identify any unexpected anatomy. The height, dominance, and patency of these structures should be considered before surgical exposure is undertaken. Neurosurgeons using this technique should be comfortable working directly over a major venous sinus, should be aware of petrous bone anatomy, and should be experienced in dissecting bone with a high-speed drill.

\section{Surface Landmarks for the Transverse-Sigmoid Junction}

It is important for neurosurgeons to be able to estimate about the location of intracranial venous sinuses using superficial landmarks. Knowing the anatomic location of the entry to the sigmoid sinus and the transverse-sigmoid junction is important for accurate placement of the initial burr hole in approaches to the posterior fossa. Traditionally, the landmark for the transverse-sigmoid junction has been the asterion (23); however, anatomical studies have shown that this bony landmark is not an accurate identifier for this venous junction $(3,17,18)$. Our findings and those of Ribas et al. (18) indicate that the asterion is located a relatively consistent distance from the transverse and sigmoid sinuses. In accord with this, Ucerler and Govsa (23) investigated 100 skulls and found the asterion located superficial to the transverse-sigmoid sinus junction in $87 \%$, inferior to the junction in $11 \%$, and superior to the junction in $2 \%$. In an anatomical study of 100 skulls (200 sides), Tubbs et al. (22) used a horizontal line (the zygomatic line) parallel to the superior border of the zygomatic arch and a vertical line (the mastoid line) passing parallel to mastoid notch and extending perpendicular to the zygomatic line. They identified the location of the transverse-sigmoid sinus junction as a point slightly inferior and medial to the junction of these two lines. We concur that the asterion is always medial to the mastoid line identified by Tubbs et al; however, it is frequently inferior to the zygomatic line that these authors used, and it is consistently related to the inferior border of the transverse sinus. Ribas et al. (18) studied 25 adult skulls and found that the transverse-sigmoid sinus junction was, on average, $1 \mathrm{~cm}$ anterior to the asterion across the petromastoid suture. Our morphometric findings correspond closely with this, as we observed the asterion approximately $5 \mathrm{~mm}$ above the inferior border of the transverse sinus and approximately $16 \mathrm{~mm}$ lateral to the sigmoid sinus.

\section{Burr Hole Placement}

It is not safe to cut the bone over the sigmoid sinus using a high-speed drill because the sinus is embedded in and adherent to a bony groove in the mastoid bone and there is significant risk of damage; thus, a safer burr-hole site is needed. Raza and Quinones-Hinojosa illustrated burr-hole placement for the both approaches anterior to the sigmoidtransverse sinus junction, and these authors performed a single craniotomy cut across the two venous sinuses (16). However, the positions of the craniotomy and burr hole over the sinuses are critical, and care is needed to prevent injury to the sinus walls. Another consideration is potential bleeding from the diploic vein, which penetrates the mastoid bone and drains into the sigmoid sinus. Our results suggest that the safest placement of the burr hole for both approaches is $5 \mathrm{~mm}$ inferior and $15 \mathrm{~mm}$ medial to the asterion. Once the burr hold is made at this site, the surgeon can enlarge the craniotomy by carefully drilling the bone superiorly and laterally until the transverse-sigmoid sinus junction is exposed. 


\section{CONCLUSION}

The number of cadavers we dissected was relatively small; however, our findings indicate that the laterally extended retrosigmoid approach offers neurosurgeons approximately $50 \%$ larger angle of view and a shorter working distance than the traditional approach provides. This modification is simple and safe to perform, and permits access to the ventral brainstem and tentorium without requirement for cerebellar retraction. This extended approach is particularly advantageous for surgical treatment of vascular lesions of the posterior cranial fossa, as well as tumors and cysts in this region or vascular compression syndromes.

\section{ACKNOWLEDGEMENTS}

Authors are thankful to Barış Coskunuzer for his intellectual contributions about calculations and Husniye Hacioglu for her helps about the figures and drawings

\section{DISCLOSURE}

Cadavers were kindly provided by the Institute of Neurological Sciences, Marmara University. The authors report no conflict of interest concerning the materials or methods used in this study or the findings specified in this paper.

\section{REFERENCES}

1. Abolfotoh M, Dunn IF, Al-Mefty O: Transmastoid retrosigmoid approach to the cerebellopontine angle: Surgical technique. Neurosurgery 73 Suppl 1:16-23, 2013

2. Al-Mefty O, Fox JL, Smith RR: Petrosal approach for petroclival meningiomas. Neurosurgery 22(3):510-517, 1988

3. Avci E, Kocaogullar Y, Fossett D, Caputy A: Lateral posterior fossa venous sinus relationships to surface landmarks. Surg Neurol 59(5):392-397, 2003

4. Baldwin HZ, Miller CG, van Loveren HR, Keller JT, Daspit CP, Spetzler RF: The far lateral/combined supra- and infratentorial approach. A human cadaveric prosection model for routes of access to the petroclival region and ventral brain stem. J Neurosurg 81(1):60-68, 1994

5. Cho CW, Al-Mefty O: Combined petrosal approach to petroclival meningiomas. Neurosurgery 51(3):708-716, 2002

6. Ciric I, Zhao JC, Rosenblatt S, Wiet R, O'Shaughnessy B: Suboccipital retrosigmoid approach for removal of vestibular schwannomas: Facial nerve function and hearing preservation. Neurosurgery 56(3):560-570, 2005

7. Day JD, Kellogg JX, Tschabitscher M, Fukushima T: Surface and superficial surgical anatomy of the posterolateral cranial base: Significance for surgical planning and approach. Neurosurgery 38(6):1079-1083, 1996

8. Deshmukh VR, Albuquerque FC, Zabramski JM, Spetzler RF: Surgical management of cavernous malformations involving the cranial nerves. Neurosurgery 53(2):352-357, 2003
9. Gonzalez LF, Alexander MJ, McDougall CG, Spetzler RF: Anteroinferior cerebellar artery aneurysms: Surgical approaches and outcomes-a review of 34 cases. Neurosurgery 55(5):1025-1035, 2004

10. Heros RC: Lateral suboccipital approach for vertebral and vertebrobasilar artery lesions. J Neurosurg 64(4):559-562, 1986

11. Jackler RK, Whinney D: A century of eighth nerve surgery. Otology \& Neurotology 22(3):401-416, 2001

12. Kawase $T$, Toya $S$, Shiobara R, Mine T: Transpetrosal approach for aneurysms of the lower basilar artery. J Neurosurg 63(6):857-861, 1985

13. Magnan J, Barbieri M, Mora R, et al: Retrosigmoid approach for small and medium-sized acoustic neuromas. Otology \& Neurotology 23(2):141-145, 2002

14. Ojemann RG: Retrosigmoid approach to acoustic neuroma (vestibular schwannoma). Neurosurgery 48(3):553-558, 2001

15. Quinones-Hinojosa A, Chang EF, Lawton MT: The extended retrosigmoid approach: An alternative to radical cranial base approaches for posterior fossa lesions. Neurosurgery 58(4 Suppl 2):208-214, 2006

16. Raza SM, Quinones-Hinojosa A: The extended retrosigmoid approach for neoplastic lesions in the posterior fossa: Technique modification. Neurosurg Rev 34(1):123-129, 2011

17. Rhoton AL Jr: The cerebellopontine angle and posterior fossa cranial nerves by the retrosigmoid approach. Neurosurgery 47 Suppl 3:93-129, 2000

18. Ribas GC, Rhoton AL Jr, Cruz OR, Peace D: Suboccipital burr holes and craniectomies. Neurosurg Focus 19(2):E1, 2005

19. Shelton C, Alavi S, Li JC, Hitselberger WE: Modified retrosigmoid approach: Use for selected acoustic tumor removal. American Journal Of Otology 16:664-668, 1995

20. Silverstein H, Nichols ML, Rosenberg S, Hoffer M, Norrell H: Combined retrolabyrinthine-retrosigmoid approach for improved exposure of the posterior fossa without cerebellar retraction. Skull Base Surgery 5(3):177-180, 1995

21. Spetzler RF, Daspit CP, Pappas CT: The combined supra- and infratentorial approach for lesions of the petrous and clival regions: Experience with 46 cases. J Neurosurg 76(4):588-599, 1992

22. Tubbs RS, Loukas M, Shoja MM, Bellew MP, Cohen-Gadol AA: Surface landmarks for the junction between the transverse and sigmoid sinuses: Application of the "strategic" burr hole for suboccipital craniotomy. Neurosurgery 65 Suppl 6:37-41, 2009

23. Ucerler $\mathrm{H}$, Govsa F: Asterion as a surgical landmark for lateral cranial base approaches. J Cranio-Maxillo-Fac Surg 34(7):415420, 2006 